\title{
Chinese overseas doctoral student narratives of intercultural adaptation
}

Article

Accepted Version

Ye, L. and Edwards, V. (2015) Chinese overseas doctoral student narratives of intercultural adaptation. Journal of Research in International Education, 14 (3). pp. 228-241. ISSN 1741-2943 doi: https://doi.org/10.1177/1475240915614934 Available at https://centaur.reading.ac.uk/45166/

It is advisable to refer to the publisher's version if you intend to cite from the work. See Guidance on citing.

To link to this article DOI: http://dx.doi.org/10.1177/1475240915614934

Publisher: Sage

All outputs in CentAUR are protected by Intellectual Property Rights law, including copyright law. Copyright and IPR is retained by the creators or other copyright holders. Terms and conditions for use of this material are defined in the End User Agreement.

\section{www.reading.ac.uk/centaur}

\section{CentAUR}

Central Archive at the University of Reading

Reading's research outputs online 
Chinese overseas doctoral student narratives of intercultural adaptation

\section{Lily Ye and Viv K Edwards*}

University of Reading, UK

Beijing Institute of Fashion Technology, P. R. China

Accepted for publication in the Journal of Research in international Education 14(3)

\section{Abstract}

This study aims to explore how Chinese overseas doctoral students adjust to a different academic, social and cultural environment, using Giddens' theoretical framework of self-identity (1991). The findings indicate the participants proactively used various coping strategies in meeting challenges, and adapting to new social environments. Continuity and stability of selfidentity were achieved either culturally or academically through self-reflexivity, autonomy, creativity, authenticity, and reliance on an ontological identity. The result is to challenge the grand narrative of essentialised "problematic Chinese learners".

\section{Keywords}

Chinese doctoral students; intercultural communication; identity; international education; self-reflexivity; study abroad

\section{Introduction}


The UK is currently one of the principal destinations for those travelling abroad in order to study. According to UKCISA (2015), there were over 80,000 mainland Chinese students studying in the UK in academic year $2013 / 14$ - the largest group of international students in this market. The present study explores a topic which has received very little attention to date, namely the identity negotiation of Chinese doctoral students during their stay in the UK. We will start with a brief discussion of previous research in this area and a justification of the choice of Giddens' theory of self-identity as the theoretical framework for the study. Analysis of narratives collected in one-toone semi-structured interviews with $11 \mathrm{PhD}$ students from a range of disciplines will then be used to offer fresh insights on how they coped with the new academic environment and to point to implications for those involved in international education.

\section{Previous studies on Chinese international students}

Several themes emerge from the growing number of studies of Chinese international students. Among the earliest writers on this subject, Jin and Cortazzi (1993) discuss communication issues for Chinese students at British universities and their supervisors (dissertation advisers), created by the alleged gap between British and Chinese ways of thinking, associated with notions such as individual versus collective cultures. Various other writers, including Li (2007) and Edwards et al. (2007), explore the challenges faced by Chinese students primarily from the perspective of university teachers, focusing on issues such as low levels of competence in English and pastoral care. In a similar vein, Huang (2008) explores differences between the 
understanding of 'critical thinking' on the part of Masters' students in Tourism and Hospitality and that of their teachers.

Increasingly, however, assumptions about the cultural differences assumed to explain the 'problems' of Chinese students are being subjected to critical scrutiny. Stephen (1997, p.115), while recognizing that such explanations 'have a surface appeal', argues that they 'should be seen as part of a historically situated and contested discourse'. Other researchers within the field of intercultural education, too, take issue with the widespread essentialisation of China and the ways in which assumed cultural differences lead researchers into the trap of 'othering' Chinese students. For this reason, Dervin (2009) advocates 'a move away from culturalism and essentialism' towards a consideration of the 'diverse diversities' of students (see also Feng, 2009).

A parallel development, then, is the growing reluctance to treat Chinese students as a homogenous group. Grimshaw (2007, p.308), for instance, advocates that "rather than accepting explanations of Chinese students that are based on exotic stereotypes, we should seek to relate to them first and foremost as people". Edwards and An (2006) and Cross and Hitchcock (2007) also provide support for this position.

A final strand of research on Chinese international students focuses on negative experiences, such as marginalisation, perceived discrimination, prejudice, stereotypes and racism (see, for instance, Coates, 2006; Brown 2009; Tian and Lowe, 2009). 
While previous studies have explored the intercultural experiences of undergraduate and postgraduate students at Masters level (e.g. Ding, 2009; Wu, 2014), the present study is based on Chinese PhD students. In moving away from the essentialism and 'othering' of much earlier work, it aims to address the complexities and nuances of the identity formation and negotiation of Mainland Chinese doctoral students in the UK, and to examine the extent to which individual experiences within an intercultural setting can influence understanding of self. It is hoped that the findings of this study will inform the future development of the internationalisation of higher education.

\section{Theoretical framework}

Much of the existing research on Chinese international study has been undertaken explicitly or implicitly within the framework of cultural studies (e.g. Abubaker, 2008) or acculturation theory (e.g. Yu and Wang, 2011). In contrast, the present study, with its focus on identity negotiation, is underpinned by Giddens' (1991) concept of "the reflexive project of the self" in which identity is seen as unfixed, fragmented, socially constructed, and reflexive. Consistent with the authors' aim to avoid 'othering', this approach challenges the notion of identity as categorised, essentialised, imposed and united, and departs in important respects from other studies of the intercultural adaptation of Chinese students.

Firstly, in a post-traditional world where opinions are no longer considered to be influenced by long standing customs, self-identity is not anchored in 
traditional collective categories such as ethnicity, gender, age or social class. In other words, it is not something that is simply given, but rather is understood in terms that are "coherent, yet continuously revised, biographical narratives" (Giddens, 1991, p.5). The emphasis, then, is on the role of narrative in understanding the Self. As Stivers (1993, p.412) points out:

The sense of self is an essentially narrative phenomenon; people conceive of themselves in terms of stories about their actions in the world, using them to make sense of the temporal flow of their lives. We find identity and meaning as a result of the stories we tell about ourselves or that others tell about us.

Secondly, self-identity is created and maintained through continuous selfobservation and self-introspection. The self manages and maintains the continuity of the narrative by means of constant self-reflexivity, through which a sense of 'ontological security' (Giddens, 1991, p.243) - or order and continuity - is achieved. This process allows past biographical narratives to be interpreted from the standpoint of the present; it also plays an important part in accommodating new experiences, events and information.

Thirdly, the reflexive project of the self is governed by the moral principle of authenticity in order to ensure that individuals are "true" to themselves. Choice and life-planning, which involve calculated risk taking, are very important mechanisms in the reflexive project of the self, in which "we are not who we are, but what we make of ourselves" (Giddens, 1991, p.75). Individuals 
reflexively create their self-identity by choosing between different life paths. In the period of late modernity, where choices are no longer constrained by tradition, individuals have to make "internally referential" choices which involve "the creation of a personal belief system by means of which the individual acknowledges that his first loyalty is to himself" (Giddens, 1991, p.80).

It is hoped that the current study will contribute to the growing body of empirical research (e.g. Lawson, 2010; Cook, 2008) underpinned by Giddens' notion of reflexive self.

\section{Research methodology}

The research question posed by this study is: how do Chinese doctoral students negotiate their identity as they adapt to a different academic and sociocultural environment? In order to answer this question, semi-structured interviews were conducted as part of a larger study with $11 \mathrm{PhD}$ students (four males and seven females), aged between 26 and 39, from a range of disciplines (Applied Linguistics, Chemistry, Design Innovation, Education, Electrical and Electronic Engineering, Finance, and Information Management and Systems). The students were recruited for the study through personal social networks, building on the insider status of one of the authors, Lily Ye (LY), as a fellow PhD student and Chinese speaker. The interviews were conducted in Chinese. However, the quotes used in the analysis which follows have been translated by LY and corroborated by a colleague fluent in both English and Mandarin. 
The inductive analysis (Denzin and Lincoln, 2000, p.389) which follows was guided by the research question, the theoretical underpinnings, the existing literature, and the themes emerging from the data. The unit of coding was an "extended account" (Riessman, 2000, p.7), which consisted of block interview quotes reflecting participants' comments on a given topic. Member-checking and triangulation based on different data sources (interviews and focus group discussions) were used in order to ensure rigour; however, we draw only on interview data in the present paper. Issues of reflexivity (Hammersley and Atkinson, 1983), of particular importance given LY's insider status, were addressed throughout the study to maximise the trustworthiness of the findings.

\section{Findings and discussion}

All the participants explained how they coped with the new environment and the various strategies they used to adapt and adjust to their new lifestyle. Five interrelated themes recurred throughout their narratives: self-reflexivity, creativity, ontological identity, autonomy, and authenticity. In the discussion that follows, the interviewee names are pseudonyms in order to preserve the anonymity of the participants.

\section{Self-reflexivity}


The first main theme that emerged from the data is self-reflexivity. For Giddens (1991, p.76), self-reflexivity, or the reflexivity of the self, is specific to late modernity:

The reflexivity of the self is continuous, as well as all-pervasive. At each moment, or at least at regular intervals, the individual is asked to conduct a self-interrogation in terms of what is happening [...]

Reflexivity in this sense belongs to the reflexive historicity of modernity, as distinct from the more generic reflexive monitoring of action.

Studying abroad encourages the self-reflexivity essential for stimulating reflection, self-exploration and self-critique, and for eventually facilitating intercultural adaptation. For example, Yuanyuan, a second year PhD student (aged 39) recounted:

I can tell you a story about my part-time job. When I was working in the coffee bar of the library on a Saturday, I had a supervisor with me. She was originally working in another bar. When the company restructured to reduce costs, she also became the supervisor in this bar. But there was a problem - she was not very familiar with our bar In fact I knew more than her. So what I tried to do was just to complete all the tasks in a typical Chinese way without thinking too much of other things. Later on I realised that even though I was working extremely hard, the supervisor might feel threatened because l'd been doing something which was supposed to be done by a supervisor. She told me this indirectly when something happened with another member of 
staff. For Chinese people it is always good to do something for other colleagues, but here it is a different story. Everyone has clear responsibilities determined by their "identity". You should always mind your own business.

The practice of self-reflexivity enables Yuanyuan to question her own perspective and show empathy towards others through self-interrogation. While it does not radically change her self-identity, it facilitates her intercultural adaptation. On the level of theory, this excerpt demonstrates how a successful intercultural experience demands heightened cultural awareness in interactions with others, and a re-appraisal of one's own culture and ways of thinking, entering the realm of "discursive" consciousness. The implication is that self-reflexivity empowers Yuanyuan in terms of "keeping the narrative going" in the new environment by adopting recognised social roles in situated contexts. Over time, it has the potential to accelerate her social inclusion in the second language setting.

Another participant, Xiulian, a second year female PhD student (aged 30) working on design innovation, was able to give a further example of how selfreflexivity can play an especially significant role in identity formation:

I think I should communicate more with my supervisor. Of course, the supervisor should also approach students but the student must be proactive. During the first six months of my $\mathrm{PhD}$, I was rather passive. It was always my supervisor who arranged the meetings on a weekly 
basis, telling me what to do and asking me to show her what I had written etc. Everything was initiated by my supervisor at that time. Then my supervisor became less proactive in approaching me and our meetings changed to a fortnightly or even a monthly basis. I was worried about it although I believed she would arrange meetings whenever she was free. I was a bit childish at that time. As I felt quite pressurised when meeting up with the supervisor, I subconsciously tried to avoid meeting with her. So I never took the initiative. In my second year, I understood what was happening - she was waiting for me to come to her and I was waiting for her to contact me. So something went wrong between us. Later we had a conversation trying to sort it out. I realised that I should not feel pressured and actually it would really help to meet up with her. So I adapted and adjusted and things have improved a lot.

Xiulian understands that her position as a PhD student in relation to her supervisor has changed over time as she has come to understand the nature of doctoral study and the supervisory relationship in UK universities. She was able to reflexively re-organise experiences from the standpoint of the present so as to maintain a biographical narrative through time and space, achieving a greatly improved relationship with her supervisor in the process.

Another participant, Zhiqiang, a 32 year old doctoral student and applied linguist, similarly drew upon self-reflexivity as a resource to maintain his identity in the intercultural setting: 
I used to seek help from the secretary of our college, for example, where and how to find something. I found out later that they may help you out a few times but you just cannot keep on asking. You need to explore by yourself. They won't keep helping you forever. So one year after I came here, I started to sort out most things by myself. Only for something truly beyond my ability, will I seek help from others. This is quite different to what happens in China, where I can keep asking help from others. Here is different. As it is not a part of their job, they won't keep doing it for you. I could read their emotions after a while and I realised what was happening. Now I understand it. Do not ask other people to do anything beyond their responsibilities.

This excerpt, too, demonstrates how self-reflexivity facilitates intercultural adaptation, and improves the quality of experience, changing students' view of themselves and the people around them. In short, all three narratives indicate that self-reflexivity and intercultural adaptation are dynamically interrelated processes which lead to a deeper understanding of the self and the new sociocultural field.

\section{Creativity}

The second emergent theme is creativity. As explained by Giddens (1991), involvement in a creative way with others and with the social world requires the individual to transcend their own habits of understanding or thinking. The 
discussion which follows, then, will focus on how individuals use their creativity to safeguard their self-identity. The data here will be presented under two main headings: the perceived language problem and perceived discrimination.

\section{Perceived Language Problem}

The perceived language problem is demonstrated in the following exchange:

LY: Is language a problem for you here?

Jianjun: I am such a person. People think my oral English is quite rubbish but I think it is OK. I just talk and others understand sooner or later.

LY: You now teach (engineering) in English although you are not a native speaker. Do you feel stressed? Do you feel that it would be better if you were a native speaker?

Jianjun: I've never felt that way. What do you learn from me? My English or my knowledge? If you want to learn English, just go and find someone on the street, who has a standard accent - is it necessary? Because you are here to learn content, what I give you is the content. So the suggestion that I make to teaching assistants like me is to 
persuade your students, using logic. Moreover, it depends on your ability to react ...

In order to sustain a coherent sense of his teaching self, Jianjun, a 28 year old PhD student in engineering who works as a teaching assistant, has to protect himself against potential threats to his perceived identity. Teaching in a British university demands a high level of English proficiency. As a non-native speaker of English, Jianjun lacks the linguistic capital highly valued in the new academic field, something which might be seen as a potential threat to his feelings of ontological security. However, he draws upon resources such as his educational capital (subject knowledge and logical reasoning) to create a confident narrative which allows him to claim ownership of English. As Widdowson (1994, cited in Fernández, 2005, p.89) points out, "to own a language is to be able to affirm oneself through it and to adapt it to one's own meaning and wishes".

Rather than portraying himself as an incompetent non-native English speaker, Jianjun builds confidence and successfully negotiates legitimacy as a second language (L2) speaker. In his narrative, he creatively positions himself as a resilient multi-competent L2 user (Cook, 2002), underlining the relevance of personal agency in the process. As Song (2013, p.5) suggests, "with strong personal agency, marginalized people are capable to author the world from their own perspectives, fashion themselves alternative positions in given discourses, and create more space to negotiate their legitimacy in the mainstream community." 
In a similar vein, Jiayi, a second year female engineering doctoral student, demonstrates the agency, creativity and reflexivity which allow her to actively take ownership of her self-identity:

When I had just come to the UK, I was so nervous when answering the telephone. I was worried that other people could not understand what I was saying, or that I could not understand them. Later on I was not that nervous any more. If they could not understand me, I just repeated it two or three times. It was even easier to talk face-to-face, as you could use body language to help. English people are good at making sense of your words. As long as they pick out several key words, they will understand what you are talking about. It was getting better and better. I did not care too much about the past tense or the present tense etc. As long as I could deliver the information, it was just fine. What else do you want to do? Life is just like this. Even in communication between Chinese people, who cares about the grammar? As long as you can make yourself understood, nothing else is important.

This excerpt shows how Jiayi's creativity protects her sense of ontological security in the face of the threat from her level of English proficiency. She works reflexively to claim her legitimate right to speak English and successfully manages the threats posed to her identity. This creativity allows her to define herself as a multi-competent L2 user and "legitimate speaker" 
(Bourdieu, 1977, p.650) rather than a passive non-native speaker; she refuses to accept native speakers as her "frames of reference" (Huang and Zhu, 2006), defining herself as a competent user of English as opposed to an "imperfect or deficient speaker of British or American standard English" (Ferguson, 2008, p.146) or an incompetent English language learner. Indeed, as Ryan (2006, p.24) points out: "a language functioning on the global scale of present-day English alters our sense of ownership of the language; the distinctions between the learner and the user become blurred".

\section{Perceived discrimination}

Creativity is also evident in student accounts of perceived discrimination. It would seem that participants in the present study are not particularly troubled by this discourse in relation to Chinese students (e.g. Grimshaw, 2008). For example, Luyao, a 27 year old chemistry $\mathrm{PhD}$ student, comments:

\footnotetext{
I think some Chinese students are not confident because we come from a developing country. When the people here look at them, they feel they are being discriminated against - racial discrimination. You are just not confident enough. Why do you always think other people are discriminating against you? In what ways are you worse than others?
}

Luyao demonstrates her strong self-belief, refusing to position herself as a victim of racial discrimination. Instead she creatively redefines herself as 
resistant to the disadvantageous status ascribed to Chinese international students.

Jianjun views the situation in a similar way:

Many (international) students might say they have experienced discrimination in the UK. But why? Why would someone discriminate against me? There would have to be something you hadn't done correctly. Of course we cannot rule out the possibility of racial factors, but I don't think this is the main reason. When you have a high level of intellectual achievement, or knowledge and experience, for example, a $P h D$, you should take the whole situation into account. This is socalled maturity following so many years' education. If you always think you are weak, you will constantly feel you are being discriminated against. However, if you are very confident, even when the same thing happens to you, you will just think the other people may be jealous, joking or in a bad mood when they say something [negative] to you.

Thinking creatively and reflexively, Jianjun manages to safeguard his sense of ontological security from potential threats caused by perceived racial discrimination. He rejects the discourse of discrimination, refusing to allow himself to be dubbed as inferior. His narrative reveals his strong sense of self-confidence or even superiority in relation to his self-identity, enabling him to "keep the narrative going" (Giddens, 1991).

\section{Ontological identity}


In discussing identity, it is useful to distinguish here between categorical and ontological identity (Taylor, 1998). Categorical identity refers to the social categories we are assigned according to gender, ethnicity, class or nationality. Ontological identity, in contrast, is the unique self which one wants or chooses to be, allowing the individual a coherent sense of self. For example, Tao's narrative below demonstrates that he relies upon his ontological self as a resource to build an identity consistent with his sense of self, rejecting his ascribed, essentialised social identity (as Chinese), and challenging the grand narrative which constructs the Chinese as the "sexist, oppressive, mysterious, inscrutable, exotic, and savage cultural/racial Other" (e.g. Yin, 2005, p. 149):

I don't expect other Chinese students to do the same as I do, but I always keep my own perspective on how things have to be done. In such a way, I hope I can prove to British people that the Chinese are very good. I do my best to maintain friendly relationships with the neighbours. I don't ask too much or expect to have something back for what I have done for them. I do this because I want to change the neighbours' view of Chinese students from what the media have described. Because of the cultural differences, there can be misunderstanding and I sincerely apologise for what I have done wrong. For example, when it is time for the rubbish collection, I sort out all the rubbish beforehand and push the bins out. When I see my neighbours haven't put their rubbish bins out, I do it for them. I want people to 
know we can be a part of British culture - helping each other, and contributing to the community. I always stuff my unwanted clothes into the charity collection bags. No matter how much and how old those clothes, it is my contribution to the community. I do the best I can. I try my best to do something useful for British society. I don't want British people to think otherwise.

This excerpt highlights Tao's agency in taking on the ownership of his selfformation, challenging the grand narrative of his assigned categorical identity. He carefully builds an ontological self (Taylor, 1998) - a caring, charitable, empathetic and sociable self - which helps him establish a sense of self-pride and sustain feelings of ontological security when negotiating the new intercultural field.

Ying, a 26 year old finance student, also accomplishes an ontological identity to protect herself from threats posed by perceived racial prejudice. She comments:

I firmly believe that you are an individual when you interact with them in daily life. So when they realise that you are not a "typical" Chinese in their mind, they will not judge you just because of your Chinese identity. However, initially they might have a prejudiced view of you, which is based on their view of a small number of Chinese people. But you do not need to take this personally. You just try your best to do the right thing and not care how others see you... I do not know how to describe it - maybe I am not that sensitive, because I really do not take it 
personally. It is like you do whatever you want and it does not matter to me.

Ying thus contests the marginalised and essentialised categorical Chinese cultural identity ascribed by society, and discursively constructs her ontological identity by declaring "this is not me". Rather than perceiving herself as a victim, Ying, creates her own life narrative, discussing the issue in a detached and analytical way, without referring to discourses of ethnicity. Her account can be seen as a narrative of self-protection, which helps her guard against the potential threat to her coherent sense of self posed by the contradiction between her perceived and "privileged" self-identity and the identity assigned by the society in which she now lives.

\section{Autonomy}

The fourth main theme that emerges from this research concerns autonomous learning, i.e. "the capacity to take control of one's own learning" (Benson, 2001, p.47). Autonomy, personal and intellectual independence, and confidence are among the qualities required if doctoral students are to develop as researchers in their specialised fields (Hockey, 1991; Johnson, Lee \& Green, 2000; Phillips, 1994; Ryan \& Zuber-Skerritt, 1999). Wright and Lodwick (1989), for instance, report that students who work independently of their supervisors and plan their own work are more likely to succeed. 
The earlier discussion focussed on the way in which students' creativity allowed them to define themselves as 'legitimate speakers'. The fact that participants in the present study contest the notion that they are imperfect English speakers or incompetent language learners, however, should not be taken to indicate that English language learning is not a major challenge for Chinese doctoral students. The narratives which follow illustrate how they use their autonomy to take responsibility for their own learning, and how they cope with difficulties they encounter in their study in relation to both language proficiency and doctoral learning.

\section{Coping with language challenges}

The data offer a number of examples of difficulties experienced by students in relation to linguistic competence. English proficiency was a constant challenge during their stay in the UK. For instance, Weiwei comments:

After you have been here for a while, you find that your English won't improve very much if you don't work hard on it. To complete the assignments you have to do the reading. When you read and prepare your own coursework, you pick up the English terminology. When you listen to the lecturers or even what other people are talking about on the street, you pick up more. Gradually you build interest in English and improve. Of course it is also useful to watch TV or listen to the radio. 
Weiwei, a 29 year old student of education, creates a narrative in which she proactively takes responsibility for her own language learning. Similarly, Luyao describes how she has coped with challenges faced in the UK. The following excerpt underlines her autonomy, agency, reflexivity and independence:

LY: What were the main challenges you have faced during study in UK?

Luyao: The biggest difficulty is always language. I am studying chemistry here, which may be different to other subjects because of the specialist terminology. For example, students who finish a BSc in the UK will know perfectly all the basic terms in English, such as oxygen and carbon dioxide etc. But for me, although I have learned all these in Chinese before, here they are simply all new words for me. I still remember when I first worked in the laboratory, I could not even say "beaker" in English. When I needed to ask for help, it was very hard for me to describe the problems in English, even for the simplest experiments. Even now it is still one of the biggest barriers for my study.

LY: How will you tackle this problem?

Luyao: You have to prepare it in advance. For example, if you want to do some experiments or discuss something, look up the dictionary and sort out all the words beforehand. 
Both Weiwei and Luyao configure their narratives in a way which portrays them as reflexive and autonomous agents able to take varying degrees of ownership for their language learning. Studying abroad has provided them with a unique opportunity to invest in language learning (Norton, 2000), accumulating the symbolic and material capitals valued in UK higher education. From a theoretical perspective, this pattern of response supports Giddens' concept of "the reflexive project of the self", in which the self acts with agency and discernment.

\section{Coping with doctoral study}

In addition to the linguistic challenges, participants have to cope with doctoral study itself. As already indicated, doctoral degree programmes emphasise learner autonomy (Johnson, Lee and Green, 2000; Phillips, 1994; Ryan and Zuber-Skerritt, 1999; Delamont and Eggleston, 1983 and Wright and Lodwick, 1989).

The present study suggests that Chinese students rely heavily on their own resources; they are autonomous learners, highly motivated and able to control their own study, using a range of strategies. Jianjun, for instance, engages in planning in advance in light of his needs and perceptions of the task in question: 
Since the beginning of my postgraduate study, I have been giving oral presentations all the time. I was so nervous the first time. I was given 15 minutes to talk followed by questions. They questioned me for about 30 minutes. Lots of Chinese students memorise what they want to say, but it doesn't work for me. I am not good at memorising things and I hate it. So I just wrote some key points for each slide and practised by myself. Do you know how I tried to conquer my nerves? I practised in front of a mirror, naked, to make myself fearless. Then I got much better in doing presentations. My presentation skills and logical thinking have both improved.

This extract illustrates how Jianjun works to craft and sustain an account of himself as an autonomous learner, narrating how he devises ways to overcome obstacles. For him, autonomy and independence are fundamental components of self-identity formation in an intercultural setting. Other strategies include publishing to meet his goals even when the support from his first supervisor is limited:

I knew clearly from the beginning that my first supervisor did not have a strong academic background in the area of my research. What could I do? I had to submit papers and read the comments of referees, and then I learned from those. I would also listen to my second supervisor. Eventually I had to prove my ability through the papers I had published. So my first supervisor was not particularly worried about me. 
Thus, by taking the initiative to write for publication, Jianjun not only develops his writing skills, but also improves his competence as a researcher. He also makes the point that feedback from a wider audience in turn promoted his self-confidence, helping enhance his academic profile and future career development.

The following exchange with Xiaogang also illustrates autonomy and agency:

LY: OK. Here is another question. Probably you had certain expectations before you started your PhD, right? So what were your initial expectations? Since you came here, have they changed in any way?

Xiaogang: At the beginning of my PhD, I hoped that when I finished I could produce something very useful, which could be applied or even used commercially. This was my initial hope. However, my project was not a good match for my academic background. After I threw myself into it, I found that what I was doing was quite different to what I had hoped. Of course this is mainly due to my lack of specialist knowledge in this area.

LY: What are you doing now to overcome this challenge or difficulty?

Xiaogang: Just trying my best - reading more literature, and talking to my supervisor to seek help. Also I will see whether my colleagues and 
friends can provide some information. Just to read more, understand the questions better and seek help from others. That's it.

The challenges faced by Xiaogang (aged 29), a third year student in engineering, were mainly caused by his weakness in subject-specific knowledge. In order to achieve academic success, he uses "resourcing" strategies (O'Malley and Chamot, 1990) to cope with the shortage of relevant theoretical knowledge, including consulting written materials (intensive reading) and other information sources when he identifies gaps in his knowledge base or encounters problems in the course of research. Through resourcing, he learns not only content knowledge but also discursive knowledge of his discipline, as well as methodological knowledge and research skills. His comments demonstrate his own resourcefulness (seeking advice from other people), agency, and learner autonomy.

The same resourcing strategies are also evident in Jiayi's narrative:

Another point is that, in fact, your first supervisor will only give you general guidance. He won't tell you everything. Your real "supervisors" are those academic papers or even research seminars. So you will have many "supervisors". Your supervisor in the project only gives you a direction but won't lead you every step there. 
Jianjun, too, emphasises reflexivity, agency and autonomy in taking ownership of academic and professional development, rather than overdependence on the host institution. He explains:

I personally feel that for PhD students, there is no need for the university to push them. If you are a PhD student, you should proactively seek both specialist knowledge and language skills. It may be determined by your temperament, but you have to make your temperament more open - to be receptive to western culture. If we are talking about undergraduate students, maybe they come here to be educated. However, as a PhD student, I come here to learn proactively. The university will not always provide all the training you may want, but rather all the learning resources for you to explore. For example, there is support in academic skills in our university. If you need help, you can always go there. However, to improve your language, you have to practise by yourself.

This excerpt not only suggests that doctoral students and host institutions should share responsibility for improving the student experience, but also highlights Jianjun's learner autonomy. In addition, his narratives question the grand narrative of the essentialised "problematic Chinese learner" as "passive, uncritical and over-reliant on the instructor" (Grimshaw, 2007, p.299).

\section{Authenticity}


The essence of authenticity is "being true to yourself" (Giddens, 1991, p.78).

In contrast with previous studies of intercultural adaptation, this study suggests that participants such as Peipei (aged 28), a final year business student, follow the principle of authenticity and egalitarianism in intercultural interaction rather than seeking opportunities for socialising with other students at all costs. By "conquering emotional blocks and tensions that prevent us from understanding ourselves" (Giddens, 1991, p.78), Peipei is now guided by her true feelings. Her personal growth is manifested in her ability to find and preserve the true self - the authentic self. She explains:

For example, I used to go out and have dinners with some 'foreigners '. Sometimes I felt that the dinner was really late, e.g. 9.00pm. However, I would not say no to them. But now I will say $9 p m$ is too late - 7pm is the latest - is that okay? In other words, let's compromise - either we have dinner at 7pm, or I am not coming.

Through a long process of reflexivity, Peipei has nurtured a sense that she is a "worthy person" (Giddens, 1991, p.79), who now feels that "one should have self-respect" and "we should treat ourselves as equal to others". She emphasises the importance of equality in any intercultural communication. In her words:

I think people should have self-respect. When I had just arrived in a foreign country, I was not very confident at all. When something went wrong, I always blamed myself. But then I slowly realised that, back to 
the questions about Chinese, we should treat ourselves as equal to all the others.

Peipei's account of her intercultural experience in the UK exemplifies the complex interplay between reflexivity and the new sociocultural field. This experience provokes questions about what has previously been taken for granted. She eventually finds a "balance point" in the new milieu, experiencing self-actualisation through being "loyal to herself". Authenticity, self-confidence and self-respect are now the core of her identity.

\section{Conclusion}

This study addressed the question of how Chinese students adapt and adjust to a different academic and sociocultural environment. Within the framework of Giddens' theory of self-identity, the discussion illustrates how participants interpret their intercultural experiences in the UK and which issues they identify as significant for their self-definition. To achieve this end, various coping strategies used by the participants in meeting challenges and adapting to the new social, cultural and academic environments in the UK were highlighted. At the centre of the analysis is individuals' self-articulation of their perceptions, experiences and themselves in relation to culture, language and identity. This approach offers the participants a chance to "speak" for themselves and to show the depths and complexities of their experiences. It also emphasises the nuances of identity formation in students, whose experiences cannot be captured in neat typologies. 
The findings indicate that participants were hard at work exercising different degrees of reflexivity and agency in the construction of their self-identities. They proactively use various coping strategies in meeting challenges and adapting to the new social, cultural and academic environments in the UK, managing to maintain a "robust" sense of narrative continuity (Giddens, 1991). Stability is achieved through self-reflexivity, autonomy, creativity, authenticity, and reliance on an "ontological self" (Taylor, 1998). Participants' narratives suggest that they are autonomous, creative, independent, positive, open, reflexive, and generally upbeat about the various challenges they face. Their collective narratives question the grand narrative of the essentialised "problematic" Chinese learner. It is therefore reasonable to argue that Chinese PhD students in the UK are not a homogeneous group, either culturally or academically. Students should be treated as individuals rather than using labels ascribed in accordance with social categories such as gender, class, ethnicity or nationality; individual voices should be heard, and individual needs should be met. Universities clearly need to be aware of the challenges that these students face, to foster staff empathy with and sympathy for students, and to create an inclusive and welcoming environment that encourages intercultural communication and enhances intercultural competency.

\section{Acknowledgement}

The authors would like to thank Dr Daguo Li from the University of Reading for valuable discussion and comments. We would also like to express our gratitude to all our participants for their time and support for this project. 


\section{References}

Abubaker A (2008) The influence of Chinese core cultural values on the communication behaviour of overseas Chinese students learning English. Arecls 5: 105-135.

Benson P (2001) Teaching and researching autonomy in language learning. London: Longman.

Berger PL and Luckmann T (1966) The social construction of reality: A treatise in the sociology of knowledge. New York: Anchor Books.

Bourdieu P (1977) Outline of a theory of practice (trans. R. Nice). Cambridge: Cambridge University.

Braun V and Clarke V (2006) Using thematic analysis in psychology. Qualitative Research in Psychology 3(2): 77-101.

Brown L (2009) International education: a force for peace and cross-cultural understanding? Journal of Peace Education 6(2): 209-224.

Coates N (2006) Learning, working and 'touching the culture': the social situation of Chinese students at the University of Salford. SEEK: Salford Environment for Expertise and Knowledge.

Cook ACH (2008) A study of identity formation in the London investment banking sector. PhD thesis. University of Warwick, Warwick Business School.

Cook V (2002) Portraits of the L2 user. Clevedon: Multilingual Matters. 
Cross J and Hitchcock R (2007) Chinese students' (or students from China's) views of UK HE: differences, difficulties and benefits, and suggestions for facilitating transition. The East Asian Learner 3(2): 1-31.

Delamont S and Eggleston J (1983) Supervision of students for research degrees. London: British Educational Research Association.

Denzin NK and Lincoln YS eds. (2000) Handbook of qualitative research. 2nd ed. Thousand Oaks, CA: Sage.

Dervin F (2009) The solidification of Chineseness in academic mobility: critical reviews of "intercultural" research articles on Chinese students. CAFIC conference paper.

Edwards V and An R (2006) Meeting the needs of Chinese students in British higher education. Available at http://ncll.org.uk/10 about/50 research/10 research projects/Meeting TheNeeds.pdf (Accessed 20 $0^{\text {th }}$ May 2014)

Edwards V, An R and Li D (2007) Uneven playing field or falling standards: Chinese students' competence in English. Race Ethnicity and Education 10(4): 387-400.

Feng AW (2009) Becoming interculturally competent in a third space. In: Feng AW Through education and training Clevedon: Multilingual Matters Ltd, pp.71-91.

Ferguson C (2008) The school-family connection: Looking at the larger picture. Austin, TX: National Centre for Community and Family Connections with Schools. 
Fernandez-Toro M (2005) The role of paired listening in L2 teaching.

Language Learning Journal 31(1): 3-8.

Giddens A (1991) Modernity and self-identity: self and society in the late modern age. Cambridge: Polity.

Gill S (2007) Overseas students' intercultural adaptation as intercultural learning: a transformative framework. Compare: A Journal of Comparative Education 37(2): 167-183.

Grimshaw T (2007) Problematizing the construct of "the Chinese learner": Insights from ethnographic research. Educational Studies 33(3): 299_ 311.

Grimshaw T (2008) Negotiating an identity in English: the discursive construction and reconstruction of Chinese students. In: University life uncovered: making sense of the student experience. Southampton: The Higher Education Academy Subject Centre for Social Policy and Social Work (SWAP), pp.56-65.

Hammersley M and Atkinson P (1995) Ethnography: principles in practice (2nd ed.). London: Routledge.

Hockey J (1991) The social science PhD - A literature review. Studies in Higher Education 16(3): 319-332.

Huang R (2008) Critical thinking: discussions from Chinese postgraduate international students and their lecturers. hospitality, leisure, sport and 
tourism network: enhancing series: internationalisation. Available at http://www.heacademy.ac.uk/assets/bmaf/documents/publications/Cas e studies/huang.pdf (accessed 20 $0^{\text {th }}$ May 2011).

Huang $Y$ and Zhu $Y(2009)$ The role of local communities and the shift of $I 2$ learners' frame of reference in second language acquisition. SFU Educational Review 1: 22-29.

Johnson L, Lee A and Green W (2000) The PhD and the autonomous self: Gender, rationality and postgraduate pedagogy. Studies in Higher Education 25(2): 135-147.

Lawson $\mathrm{H}$ (2010) Young people constructing identities in the transition to Higher Education. Unpublished DPhil thesis. University of Sussex.

Li D (2007) Coping with linguistic challenges in UK higher education: The use of strategies by Chinese research students. Language Learning Journal 35(2): 205-219.

Norton B (2000) Identity and language learning: Gender, ethnicity, and educational change. Harlow: Pearson Education.

O'Malley JM and Chamot AU (1990) Learning strategies in second language acquisition. New York: Cambridge University Press.

Phillips EM (1994) Quality in the PhD: points at which quality may be assessed. In: R Burgess (ed.) Postgraduate education and training in the social sciences. London: Jessica Kingsley. 
Riessman CK (2000) Analysis of personal narratives. Available at:

http://alumni.media.mit.edu/ brooks/storybiz/riessman.pdf (accessed on 20 January 2014).

Ryan S (2006) Language learning motivation within the context of globalization: An L2 self within an imagined global community. Critical Inquiry in Language Studies: An International Journal 3(1): 23-45.

Ryan Y and Zuber-Skerritt O (1999) Supervising non-English speaking background students in the globalized university. In: Ryan $\mathrm{Y}$ and Zuber-Skerritt O (Eds.), Supervising postgraduates from non-English speaking backgrounds. Buckingham: Open University Press, pp.3-11.

Song C (2013) Non-native English-speaking teachers' legitimacy negotiation in North American ELT classrooms. SFU Education Review. Available at: http://www.sfuedreview.org/wp-content/uploads/2013/11/SongEdRev2013.pdf (accessed 20th January 2014).

Stephens K (1997) Cultural stereotyping and intercultural communication: working with students from the People's Republic of China in the UK. Language and Education 11(2): 113-124.

Stivers C (1993) Reflections on the role of personal narrative in social science. Signs: Journal of Women in Culture and Society 18(2): 408-425.

Taylor D (1998) Social identity and social policy: engagements with postmodern theory. Journal of Social Policy 27(3): 329-350. 
Tian M and Lowe J (2009) Existentialist internationalisation and the Chinese student experience in English universities, Compare: A Journal of Comparative and International Education 39(5): 659-676.

UKCISA (2015) International student statistics: UK higher education.

Available at: http://www.ukcisa.org.uk/Info-for-universities-colleges-schools/Policy-research--statistics/Research--statistics/Internationalstudents-in-UK-HE/ (accessed on $1^{\text {st }}$ Feb 2015).

Wright $J$ and Lodwick R (1989) The process of the PhD: a study of the first year of doctoral study. Research Papers in Education 4(1): 22-56.

Wu Q (2014) Motivations and decision-making processes of mainland Chinese student for undertaking master's programs abroad. Journal of Studies in International Education 18(5): 426-444

Yin J (2005) Constructing the other: a critical reading of the joy luck club. The Howard Journal of Communications 16(3): 149-175.

Yu W and Wang S (2011) An investigation into the acculturation strategies of Chinese students in Germany. Intercultural Communication Studies 20(2): 190-210.

\section{Author biographies}

Viv Edwards is Professor of Language in Education at the University of Reading. She is editor of the international journal Language and Education, and has researched and published widely in the areas of multilingualism and education. She has worked in the field of international education and language education for over 30 years, and has successfully secured research 
grants from funding bodies including the British Council, Leverhulme Trust and Sino-British Foundation.

\section{Add a short paragraph on Lily Ye}

Dr Ye was a PhD researcher at the University of Reading. She is now a Lecturer at the Department of Foreign Languages, Beijing Institute of Fashion Technology. Her research interests include language, culture and identity, intercultural communication, ESL/ESP, international education, and fashion and culture. 